\title{
Effects of humidity and counter-surface on tribochemical wear of
}

\section{soda-lime-silica glass}

\author{
Hongtu He ${ }^{1,2}$, Linmao Qian ${ }^{1}$, Carlo G. Pantano ${ }^{2,3}$, and Seong H. Kim Ki, $^{1,3 *}$ * \\ ${ }^{1}$ Tribology Research Institute, Key Laboratory for Advanced Technology of Materials (Ministry of \\ Education), Southwest Jiaotong University, Chengdu, P.R. China 610031 \\ ${ }^{2}$ Materials Research Institute, Pennsylvania State University, University Park, PA, USA 16802 \\ ${ }^{3}$ Department of Materials Science and Engineering, Pennsylvania State University, University Park, PA, \\ USA 16802 \\ ${ }^{4}$ Department of Chemical Engineering, Pennsylvania State University, University Park, PA, USA 16802
}

\begin{abstract}
:
The effects of counter surface chemistry on the friction and wear of soda-lime-silica glass were investigated using a ball-on-flat tribometer with various ball materials (stainless steel, silicon nitride, and alumina) in dry and humid environments. It was found that the interfacial wear was very sensitive to environmental humidity and counter surface chemistry. In dry conditions, sodalime glass was damaged mechanically regardless of counter-surface materials, creating a rough and deep wear track. These results were consistent with the Archard relationship - a softer material would wear mechanically by a harder material. However, in humid conditions, the ball materials that were harder than the soda-lime glass were damaged. Thus, the wear of glass interfaces under humid conditions does not follow the Archard relationship. These results clearly show that the tribochemical reactions involving the substrate and counter surface chemistry as
\end{abstract}


well as the adsorbed water molecules are determining factors governing wear behaviors in humid environments.

Keywords: Soda-lime-silica glass, humidity, counter-surface chemistry, mechanochemical wear 


\section{Introduction}

Owing to its superior chemical and physical properties as well as cost effectiveness, multicomponent silicate glasses have been widely used for building and automotive windows, display glasses, kitchen ware, furniture etc. [1,2]. In these applications, the durability of glass surfaces is an important factor determining processability or service life of glass materials [3-7]. Thus, it is essential to understand the wear or scratch behavior of glass in various environmental conditions.

Generally, the friction and wear of materials depend on their mechanical properties (elastic modulus and hardness) and structural defects (dislocations or microcracks) [8-11]. In ambient air, they also depend on mechanochemical reactions involving adsorbed molecules impinging from the gas phase $[12,13]$. For example, it was found that wear of silicon surface could be prevented in the presence of alcohol vapor in the ambient. The adsorbed alcohol molecules could increase the energy barrier required to cleave the Si-O-Si bonds at the native oxide surface of the $\mathrm{Si}$ wafer, as compared to clean hydroxyl-terminated $\mathrm{SiO}_{2}$ surfaces [12]. For inorganic materials with drastically different chemical and topographic structures, it was reported that a monolayer of adsorbed organic molecules could lubricate the solid interfaces and result in lower friction and negligible wear of materials [13].

Not only the environmental conditions, the counter surface chemistry can also affect the friction and wear of tribological interfaces. For example, the nanowear results of silicon surfaces could vary significantly when rubbing against different counter surfaces [14-16]. A deep wear of silicon in humid environments occurred only when the counter surface was $\mathrm{SiO}_{2}$, while a hillock formation on the silicon substrate was observed when the counter surface was diamond [14]. It was believed that the silica surface was chemically reactive enough to form Si-O-Si bridging 
bonds between two sliding solid surfaces, while the diamond surface was chemically inert (or not reactive enough) to induce the tribochemical wear of silica surface. It was also observed that the nanowear of silicon surfaces could be prevented when rubbing with the $\mathrm{SiO}_{2}$ tip in ethanol vapor, and the hillock formation by the diamond tip was reduced by $\sim 80 \%$ in ethanol vapor, compared to the one formed in humid air [15]. These reports suggest that the chemical reactivity of counter surfaces play important roles in the mechanochemical wear of sliding interfaces.

Previous investigations on environmental effects reported that the friction and wear behaviors of multicomponent silicate glass substrates tested with silica and borosilicate glass balls vary drastically with humidity [17-19]. In dry conditions, glass substrates were easily scratched creating a very rough and deep wear track. When water molecules were adsorbed at the glass surface in humid environments, the wear track of glass became smooth with much lower wear width and depth. When a thin layer of adsorbed alcohol molecules was maintained by adsorption from the gas phase, no visual wear of the glass substrates was observed at the same mechanical load and sliding speed conditions [18]. Although it was not directly measured, the adsorbed alcohol layer thickness was expected to be around one monolayer in the friction test condition since the alcohol adsorption behavior on glass would be similar to that on the silica surface $[20,21]$. Thus, it was believed the wear of glass in humid environments occurs through a mechanochemical process rather than a purely mechanical one. Besides, the wear resistance of soda-lime glass increased as environmental humidity increased, which was not observed for other glasses such as fused silica, borosilicate, and aluminosilicate glasses $[18,19]$. These results indicated that the water reactivity inside the wear track of the soda-lime glass substrate being rubbed with silica or borosilicate glass balls is quite different from other glasses. 
In the present paper, the effect of counter surface chemistry is studied to better understand the friction and wear mechanism of multicomponent silicate glasses in humid conditions using a reciprocating ball-on-flat tribo-test system and various ball materials, namely Pyrex, $\mathrm{Si}_{3} \mathrm{~N}_{4}, \mathrm{Al}_{2} \mathrm{O}_{3}$, and stainless steel. It was found that the water adsorbed from the environment plays critical roles in the wear of silicate glass substrates as well as counter surfaces (balls). In dry conditions, which surface gets damaged (glass versus ball) was determined solely by the mechanical properties (such as modulus and hardness) of the solid materials. However, when scratched in humid environments, ball materials that are harder than the glass substrates were damaged. These results clearly show that the chemical reactions involving water molecules at tribological interfaces of glass materials can vary drastically depending on the counter surface chemistry.

\section{Experimental methods}

The glass substrates tested in this study were soda-lime-silica glass substrates (cut from float glass from Asahi Glass Company, Japan), borosilicate glass with an expansion coefficient $3.3 \mathrm{ppm} / \mathrm{K}\left(\mathrm{BF} 33^{\circledR}\right.$, glass slides from Schott Glass, Germany), sodium aluminosilicate glass and chemically-strengthened aluminosilicate glass $\left(\mathrm{K}^{+} / \mathrm{Na}^{+}\right.$exchanged, $0.7 \mathrm{~mm}$ thick, Corning Inc., Corning, NY). Three types of balls were used for friction and wear testing: silicon nitride $\left(\mathrm{Si}_{3} \mathrm{~N}_{4}\right)$ balls (Specialty Glass Products Inc.; diameter $=3 \mathrm{~mm}$ ), alumina $\left(\mathrm{Al}_{2} \mathrm{O}_{3}\right)$ balls (Specialty Glass Products Inc.; diameter $=3 \mathrm{~mm}$ ), and stainless steel (AISI 440C) balls (diameter $=3 \mathrm{~mm})$. These materials were selected because they are relevant to applications requiring mechanical endurance of the glass surface. The physical properties of balls and glass substrates are listed in Table 1 
$[22,23]$. The glass substrates and ball surfaces were cleaned by rinsing with ethanol followed by blow-drying with dry nitrogen gas. To ensure the reproducibility of experiment results, each experiment was repeated at least 3 times; but, only representative data are shown in this paper. More details of the cleaning and surface composition of the soda-lime-silica glass can be found in previous publications $[24,25]$.

Table 1. Physical properties of the ball and substrate materials used in the experiments.

\begin{tabular}{cccc}
\hline Materials & Hardness $(\mathrm{GPa})$ & $\begin{array}{c}\text { Young's modulus } \\
(\mathrm{GPa})\end{array}$ & Poisson ratio \\
\hline $\mathrm{Al}_{2} \mathrm{O}_{3}$ & 20 & 400 & 0.26 \\
$\mathrm{Si}_{3} \mathrm{~N}_{4}$ & 15 & 310 & 0.28 \\
Stainless steel & 7 & 200 & 0.28 \\
Soda-lime-silica glass & 5.8 & 72 & 0.23 \\
Borofloat (BF33 ${ }^{\circledR}$ ) glass & 7.3 & 67 & 0.23 \\
$\mathrm{Na}^{+}$ & 5.8 & 64 & 0.21 \\
$\mathrm{~K}^{+} / \mathrm{Na}^{+}$-aluminosilicate glass & 7.1 & 71 & 0.21 \\
\hline
\end{tabular}

A custom-built reciprocating ball-on-flat tribometer with an environmental control capability was used to study the friction and wear behavior of multicomponent glass surfaces in both dry and humid ambient conditions, as shown in Figure 1. The tribometer was operated at a sliding speed of $4.2 \mathrm{~mm} / \mathrm{s}$ and the reciprocating sliding track was roughly $3 \mathrm{~mm}$ in length. A contact load of $0.2 \mathrm{~N}$ was used for all data shown in this paper. In our previous study, it was found that the glass surface is damaged at this load condition as long as detrimental tribochemical reactions are prevented by the adsorption of one monolayer of alcohol [18]. For a silicon nitride ball compressing a soda-lime-silica glass surface, the corresponding maximum 
Hertzian contact pressure was estimated to be $\sim 400 \mathrm{MPa}$. Based on the Hertzian contact calculation, the maximum elastic deformation was estimated as $\sim 8 \mu \mathrm{m}$ deep and $30 \mu \mathrm{m}$ wide when pressed with the stainless steel (SS) ball, and $7 \mu \mathrm{m}$ wide and $30 \mu \mathrm{m}$ wide for the $\mathrm{Si}_{3} \mathrm{~N}_{4}$ and $\mathrm{Al}_{2} \mathrm{O}_{3}$ balls. The wear track was analyzed with optical profilometry (Zygo NV7300) and optical microscopy without removing the debris from the wear track.

\section{Results and discussion}

\subsection{Wear of softer glass substrates by harder counter surfaces in dry condition}

In dry condition, the friction coefficient was $0.3 \sim 0.4$ for $\mathrm{Si}_{3} \mathrm{~N}_{4}$ and $\mathrm{Al}_{2} \mathrm{O}_{3}$ ball (Figures $2 \mathrm{a}$ and $2 \mathrm{~b}$ ). The friction coefficient measured with the stainless steel was initially very high (even larger than 1) and then decreased to a range of $0.4 \sim 0.6$ as the sliding cycles continued (Figure 2c). Figure 3 shows the optical profilometry images and line profiles of both counter surface (ball) and soda-lime-silica glass substrate after rubbing for 400 cycles at an applied load of $0.2 \mathrm{~N}$ in dry condition. In all cases, the wear results under dry conditions were consistent with the Archard relationship, which predicted that for two different solids at the sliding interface, the softer material would wear more than the harder material [26]. Under the test condition used in the current study, the counter surfaces did not significantly wear, but the soda-lime glass substrates were severely worn due to interfacial friction and mechanical abrasion (or cracking), which made the wear track very rough and deep. The wear mark in the soda-lime glass substrate was typically $\sim 10 \mu \mathrm{m}$ deep and $\sim 160 \mu \mathrm{m}$ wide for scratching with $\mathrm{Si}_{3} \mathrm{~N}_{4}$ balls (Figure $3 \mathrm{a}$ ); $\sim 6 \mu \mathrm{m}$ deep and $\sim 160 \mu \mathrm{m}$ wide for $\mathrm{Al}_{2} \mathrm{O}_{3}$ balls (Figure 3b); and $\sim 13 \mu \mathrm{m}$ deep and $\sim 260 \mu \mathrm{m}$ wide for stainless steel balls (Figure 3c). 
It was intriguing to note that wear width and depth for soda-lime glass substrate were the largest for the SS ball (lowest hardness and modulus) and the smallest for the $\mathrm{Al}_{2} \mathrm{O}_{3}$ ball (highest hardness and modulus). If the physical indentation or deformation of glass substrates were the main cause for the wear of glass substrates, one would expect the largest wear of soda-lime glass substrate for the case of $\mathrm{Al}_{2} \mathrm{O}_{3}$ ball. The inconsistency of the observed results with this prediction might indicate that the interfacial bonding (like a cold-welding in the case of metal-to-metal contact) or third-body adhesion may affect the wear behavior of the glass substrate in a dry environment. The glass wear debris did not adhere to the stainless steel ball surface (Figure 3c); they were squeezed out of the contact area and piled up mostly outside the contact region. Thus, the glass surface must have been in constant contact with the stainless steel ball surface. However, in the case of silicon nitride and alumina balls, the wear debris of the glass substrate adhered to the ball surface, forming a thick transfer film protruding from the ball surface (Figures $3 \mathrm{a}$ and $3 \mathrm{~b}$ ). Thus, the interfacial shear took place mostly between the glass and the transfer film, rather than the silicon nitride or alumina surface.

\subsection{Wear of harder counter surfaces upon rubbing against softer glass substrates in humid conditions}

In contrast to the dry case, the wear behavior of the glass/ball interface in humid environments could not be explained with on the mechanical properties of the two materials involved. As shown in Figure 4, the hard ceramic balls $\left(\mathrm{Si}_{3} \mathrm{~N}_{4}\right.$ and $\left.\mathrm{Al}_{2} \mathrm{O}_{3}\right)$ were substantially worn when rubbed against a soda-lime glass substrate in humid conditions. Also, the higher

friction coefficients were higher than that in dry environment, except the case of $\mathrm{Al}_{2} \mathrm{O}_{3}$ ball 
rubbing at $90 \%$ relative humidity $(\mathrm{RH})$ condition where the friction coefficient was low (Figure 2b) and the $\mathrm{Al}_{2} \mathrm{O}_{3}$ ball wear was negligible (Figure 4b). The wear width of the ball counter surface was $\sim 100 \mu \mathrm{m}$ and $\sim 150 \mu \mathrm{m}$ for the $\mathrm{Si}_{3} \mathrm{~N}_{4}$ and $\mathrm{Al}_{2} \mathrm{O}_{3}$ balls, respectively (Figures $4 \mathrm{a}$ and $4 \mathrm{~b}$ ). However, the material removal of the soda-lime glass surface due to scratch was very small. Instead, the deposition of small wear debris on top of the glass surface was often observed. These results clearly demonstrated that the classical Archard relationship cannot explain the wear behavior of glass interfaces in humid conditions.

It is known that $\mathrm{Si}_{3} \mathrm{~N}_{4}$ can easily wear under tribo-test conditions in liquid water [27-29]. In water, the following surface reaction can occur:

$$
\mathrm{Si}_{\text {surface }}-\mathrm{N}-\mathrm{Si} i_{\text {surface }}+\mathrm{H}_{2} \mathrm{O} \rightarrow \mathrm{Si}_{\text {surface}}-\mathrm{NH}+\mathrm{Si}_{\text {surface}}-\mathrm{OH}
$$

Continuation of this reaction would produce $\mathrm{Si}(\mathrm{OH})_{4}$, which has small but measureable solubility in water [30]. The sliding action could transport this reaction product species out of the wear track. Adsorption of $\mathrm{H}_{2} \mathrm{O}$ from the gas phase can also promote this reaction, resulting in the severe chemical wear of $\mathrm{Si}_{3} \mathrm{~N}_{4}$. The chemical stability of the $\mathrm{Si}-\mathrm{OH}$ group at the nitride or oxynitride surface would be very different from that at the oxide surface. The nitride surface structure seems to make the oxidative removal of surface atoms much faster than the oxide surface [31,32]. Also, $\mathrm{Si}_{3} \mathrm{~N}_{4}$ is thermodynamically unstable with respect to oxidation [32]; the main reason that $\mathrm{Si}_{3} \mathrm{~N}_{4}$ is stable at normal conditions is because the native surface oxide layer limits oxygen transport to the subsurface nitride. Thus, if the native oxide layer is removed or damaged due to tribological action, then decomposition of silicon nitride by reaction with water can easily take place and intermediate species will be continuously removed by the reciprocating action against the glass surface. The overall tribochemical reactions could be described as[33]: 


$$
\mathrm{Si}_{3} \mathrm{~N}_{4}+12 \mathrm{H}_{2} \mathrm{O} \rightarrow 3 \mathrm{Si}(\mathrm{OH})_{4}+4 \mathrm{NH}_{3}
$$

It is very surprising that $\mathrm{Al}_{2} \mathrm{O}_{3}$ is worn upon scratching against a soda-lime glass surface at intermediate humidity conditions $(20 \%$ and $40 \% \mathrm{RH})$. Like $\mathrm{Si}_{3} \mathrm{~N}_{4}$, the wear of $\mathrm{Al}_{2} \mathrm{O}_{3}$ must be due to tribochemical reactions in the presence of water molecules adsorbed at the sliding interface [34]. Although $\mathrm{Al}_{2} \mathrm{O}_{3}$ is stable with respect to oxidation, the surface hydration of $\mathrm{Al}_{2} \mathrm{O}_{3}$ can occur by reaction with water in the air $[35,36]$ :

$$
\mathrm{Al}_{2} \mathrm{O}_{3}+\mathrm{H}_{2} \mathrm{O} \rightarrow 2 \mathrm{AlO}(\mathrm{OH})
$$

$$
\mathrm{Al}_{2} \mathrm{O}_{3}+3 \mathrm{H}_{2} \mathrm{O} \rightarrow 2 \mathrm{Al}(\mathrm{OH})_{3}
$$

Once the surface is hydrated (even if partially), then the adsorbed water molecules could react further with the surface hydroxyl groups, which could lead to formation of an amorphous or gelatinous hydroxide layer [37]. Again, when the surface hydroxide layer is removed or damaged due to tribological action, decomposition of $\mathrm{Al}_{2} \mathrm{O}_{3}$ by reaction with water can easily take place, and intermediate species will be continuously removed by the reciprocating action against the glass surface. Although $\mathrm{AlO}(\mathrm{OH})$ may not dissolve in water, $\mathrm{Al}(\mathrm{OH})_{3}$ could be dissolved from the wear track and precipitate as $\mathrm{AlO}(\mathrm{OH})$ or $\mathrm{Al}_{2} \mathrm{O}_{3}$ at some other places. It is noted that the wear of the $\mathrm{Al}_{2} \mathrm{O}_{3}$ ball and the soda-lime glass substrate is negligible at $90 \% \mathrm{RH}$ (Figure $4 \mathrm{c}$ ). Although no chemical evidence can be provided due to the difficulty of analyzing extremely small wear debris, it could be speculated that the fully hydrated gelatinous hydroxide layer on $\mathrm{Al}_{2} \mathrm{O}_{3}$ could be formed at this near-saturation humidity conditions and the high degree of hydration of this layer could induce the boundary lubrication effect. 
Even a hard steel material can badly wear when scratched against glass surfaces in humid conditions. When an AISI 440C stainless steel bearing ball was rubbed against soda-lime glass in a low RH condition $(20 \% \mathrm{RH})$, the wear track formed on the soda-lime glass substrate was only $<0.1 \mu \mathrm{m}$ deep, while the wear depth of the steel ball was $\sim 0.5 \mu \mathrm{m}$ (Figure 5). As humidity increased, the wear of the glass substrate was almost completely stopped and the wear debris of the stainless steel ball surface was adhered on the glass surface. The wear debris adhered on the glass surface appears to be very fine (Figure 5b). The drastic difference from the dry friction case (Figure 3c) suggested that the interfacial wear is not purely mechanical any more. It must be chemically-assisted (mechanochemical), which produced very fine wear debris particles. These fine particles may not be readily pushed out from the sliding interface. Then, they could be packed by the contact load and shearing forces.

In our previous study, the $440 \mathrm{C}$ stainless steel ball was also found to wear when rubbed against copper substrates in humid air, and it was attributed to the mechanochemical anodic dissolution of steel ball by galvanic corrosion [25]. However, silicate glasses are insulators and cannot promote electrochemical reactions [38], so galvanic corrosion could not be the main reason for wear of the steel ball on the glass substrates. When scratching soda-lime-silica glass in humid environments, sodium ions $\left(\mathrm{Na}^{+}\right)$in the glass can leach out and exchange with hydronium ions (or proton and an extra water) [17]. The replacement of $\mathrm{Na}^{+}$ions inside the glass with $\mathrm{H}_{3} \mathrm{O}^{+}$ or $\mathrm{H}^{+}$ions from the adsorbed water can make the adsorbed water layer on the glass basic [39]. If so, the $\mathrm{Na}^{+}$leaching from the glass could make steel ball susceptible to chemical etching under sliding contact conditions.

In order to test whether the locally basic water layer could etch the steel ball surface, wear tests were carried out with different types of glass substrates. Figure 6a display the line 
profiles of stainless steel balls after rubbing against borosilicate that does not have leachable $\mathrm{Na}^{+}$ ions. It was found the steel ball still worn off and the wear width was about $100 \mu \mathrm{m}$, similar to the soda-lime-silica glass case. Thus, the wear of stainless steel ball cannot be attributed to the etching effect in local basic conditions.

It was noted that the borosilicate glass has no wear (material removal) when rubbed with the stainless steel ball at 20\% RH (Figure 6a), while the soda-lime glass showed a mild wear at the same condition (Figure 5b). Could this be due to the difference in the hardness of these two glasses? The hardness of borosilicate glass is similar to that of stainless steel (Table 1). This hypothesis was tested and ruled out by comparing the wear behaviors of aluminosilicate glass substrates. The hardness of sodium aluminosilicate glass is comparable to that of soda-lime glass; in contrast, the chemically strengthened aluminosilicate (via $\mathrm{K}^{+} / \mathrm{Na}^{+}$exchange) has hardness higher than soda-lime glass and similar to borosilicate and stainless steel. However, both sodium and ion-exchanged aluminosilicate glasses showed the wear behavior similar to the soda-lime glass when rubbed with the stainless steel ball in humid conditions (Figures $6 \mathrm{~b}$ and $6 \mathrm{c}$ ).

Although the stainless steel surface is covered with a few nm thick corrosion-resistant chromium oxide layer, this protective layer can easily be damaged during the friction test [25]. Once the protective oxide layer is damaged, the iron phase inside the ball can be oxidized. Generally, the passivation of iron $(\mathrm{Fe})$ by water vapor can form a thin oxide layer. The oxide film formed at ambient temperature contains primarily iron oxy-hydroxide (FeOOH) [40]. If friction increases local temperature to $100-300{ }^{\circ} \mathrm{C}$, then iron hydroxide can also be formed [41]:

$$
\begin{aligned}
& 2 \mathrm{Fe}+6 \mathrm{H}_{2} \mathrm{O} \rightarrow 2 \mathrm{Fe}(\mathrm{OH})_{3}+3 \mathrm{H}_{2} \\
& 4 \mathrm{Fe}+3 \mathrm{O}_{2}+6 \mathrm{H}_{2} \mathrm{O} \rightarrow 4 \mathrm{Fe}(\mathrm{OH})_{3}
\end{aligned}
$$


It is unlikely to form $\mathrm{Fe}_{2} \mathrm{O}_{3}$ and $\mathrm{Fe}_{3} \mathrm{O}_{4}$ since these oxide phases are formed at much higher temperatures $\left(550{ }^{\circ} \mathrm{C}\right)[40]$. The oxidation kinetics of steel can increase its rate by 4 orders during the friction test, because the extensive plastic deformation can create diffusion pathways for water into the bulk [27]. It was reported that iron oxide and iron hydroxide was formed inside the worn surface after wear tests [42]. Thus, the oxidative wear of steel must be the main reason for the wear of steel ball $[43,44]$. Note that this does not rule out any possible contributions from wear debris or ions originated from the glass surface.

\subsection{Implication into tribochemistry of glass in humid environments}

In general, tribochemical wear of glass surfaces takes place in humid environments, while mechanical wear mechanisms dominate in dry conditions. The mechanical wear process depends to some extent on the mechanical properties of the two solids and their interfacial reactions while sliding against each other. Silicate glass materials are softer than $\mathrm{Si}_{3} \mathrm{~N}_{4}, \mathrm{Al}_{2} \mathrm{O}_{3}$, and stainless steel; thus, the counter surface (ball) will cause severe mechanical wear of glass in dry condition. This can be accompanied by micro-cracking or pitting of the glass under the shear contact region, which results in the creation of rough wear tracks. In contrast, adsorbed water on the glass surface in humid conditions induces tribochemical reactions during the reciprocating friction cycles. Since the sliding force is dissipated mostly at the interface involving adsorbed molecules, rather than inducing the subsurface shear of the glass, micro-cracks or pits of the subsurface are not formed. Thus, the wear track that formed in a humid condition was much smoother than the wear track produced in a dry condition. The specific tribochemical reactions that take place at the 
sliding interface depend on not only the environments (adsorbing species) but also the relative chemical reactivity of the substrate and ball surfaces $[45,46]$.

Tribochemical or mechanochemical reactions are ubiquitous at sliding interfaces of various materials in humid environment $[13,14,18,25]$. For glass materials, stress-enhanced hydrolysis has been considered as the major reason, because the tensile stress can facilitate hydrolysis of the Si-O-Si network. This reaction is called stress corrosion and is responsible for the enhanced propagation rate of cracks in most silicate glasses in humid conditions $[47,48]$. However, this stress corrosion process alone cannot explain the humidity dependence of wear for glass materials upon tangential or interfacial sliding [19]. Our previous studies found that borosilicate and aluminosilicate glasses show an increase in wear as the humidity of the environment increases, while soda-lime-silica glasses exhibit a decrease in wear as the humidity approaches the saturation point [17-19]. This peculiar humidity dependence of soda-lime glass is not fully understood yet, but it is speculated that the presence of leachable sodium ions and the chemical reactivity of the water species occupying the sodium-leached sites must play some roles [17].

The results reported in the current study reveal another important aspect that has not been recognized in previous studies. Not only the type of glass network and presence of water, but also the surface chemistry of the counter-sliding material is a key determinant in the tribochemical wear of glass interfaces. When wear of the glass substrate was tested with silica or borosilicate (pyrex) glass balls in humid environments, the wear debris of the substrate adhered to the ball surface, forming a thick transfer film; thus, the shear action was mostly at the interface of the substrate and its own wear debris, rather than at the interface of substrate and ball materials [18]. However, when the wear test was carried out with stainless steel, $\mathrm{Si}_{3} \mathrm{~N}_{4}$, and 
$\mathrm{Al}_{2} \mathrm{O}_{3}$ balls in humid conditions, the situation appeared to be completely different. In low humidity (RH 20\%), the glass surfaces tested here showed a very mild wear, much smaller compared to the wear observed with the silica and borosilicate glass balls. At this low humidity, the water supply might have been insufficient for complete prevention of mechanical wear. The adhesion of the glass wear debris to the $\mathrm{Si}_{3} \mathrm{~N}_{4}, \mathrm{Al}_{2} \mathrm{O}_{3}$, and stainless steel balls was not observed. At RH $40 \%$ and $90 \%$, the glass substrate wear was negligible while the ball surface wear was significant, even though the modulus and hardness of the ball materials were larger than the glass substrate materials. The absence of glass wear under these conditions suggested that tribochemical wear of glass occurs readily only when the counter surface is the same materials (transfer films on the counter surface); when the wear debris does not adhere to the counter surface (as in the case of $\mathrm{Si}_{3} \mathrm{~N}_{4}, \mathrm{Al}_{2} \mathrm{O}_{3}$, and stainless steel), water-induced tribochemical wear does not take place readily.

\section{Conclusion}

In inert environments, the wear of soda-lime-silica glass rubbed with alumina, silicon nitride, and stainless steel counter surfaces could be explained by the Archard relationship that predicts wear of a softer material by a harder material. However, in humid ambient, the sodalime-silica glass surface induced wear of the ball counter surfaces even though the ball materials were harder than the soda-lime glass substrate. These results indicated that which surface will be damaged in humid conditions is determined not by the material hardness, but by mechanochemical reactions involving the adsorbed water molecules, probably hydrolysis reactions assisted by interfacial shear. 


\section{Acknowledgement}

This work was supported by the National Science Foundation (Grant No. DMR-1207328). HH was supported by the Research Exchange program of the NSF International Materials Institute for New Functionality in Glass (Grant No. DMR-0844014). HH and LQ were supported by the Natural Science Foundation of China (51175441, 51375409). The authors acknowledged Asahi Glass Company, Schott Inc. and Corning Inc. for providing samples for this study.

\section{Reference}

[1] E. Axinte, Glasses as engineering materials: a review, Mater. Des. 32, (2011) 1717-1732.

[2] S. Karlsson, B. Jonson, C. Stalhandske, The technology of chemical glass strengthening a review, Glass Technol.: Eur. J. Glass Sci. Technol. A 51, (2010) 41-54.

[3] Y.G. Wang, L.C. Zhang, A. Biddut, Chemical effect on the material removal rate in the CMP of silicon wafers, Wear 270, (2011) 312-316.

[4] P.V. Kolluru, D.J. Green, C.G. Pantano, C.L. Muhlstein, Effects of Surface Chemistry on the Nanomechanical Properties of Commercial Float Glass Surfaces, J. Am. Cer. Soc., 93, (2010) $838-847$.

[5] T. Kusumi, Y. Sato, Y. Akagami, U. Umehara, New polishing method using water-based slurry under AC electric field for glass substrate, J. Magn. Magn. Mater. 323, (2010) 1394-1397.

[6] C.G. Pantano, Surface Chemistry in Relation to the Strength and Fracture of Silicate Glasses, pp. 37-66 in Strength of Inorganic Glass, Edited by C. R. Kurkjian. Plenum, New York, 1985. 
[7] L.M. Cook, Chemical processes in glass polishing, J. Non-Cryst. Solids 120, (1990) 152-171.

[8] R. Ribeiro, Z. Shan, A.M. Minor, H. Liang, In situ observation of nano-abrasive wear, Wear 263, (2007)1556-1559.

[9] J.X. Yu, L.M. Qian, B.J. Yu, Z.R. Zhou, Nanofretting behaviors of monocrystalline silicon (100) against diamond tips in atmosphere and vacuum, Wear 267, (2009) 322-329.

[10] B.Bhushan, Contact mechanics of rough surfaces in tribology:multiple asperity contact, Tribol. Lett. 4 (1), (1998) 1-35.

[11] B. Yu, X. Li, H. Dong, Y. Chen, L. Qian, Z. Zhou, Towards a deeper understanding of the formation of friction-induced hillocks on monocrystalline silicon, J. Phys. D: Appl. Phys. 45, (2012) 145301.

[12] A.L. Barnette, D.B. Asay, D. Kim, B.D. Guyer, H. Lim, M.J. Janik, S.H. Kim, Experimental and density functional theory study of the tribochemical wear behavior of $\mathrm{SiO}_{2}$ in humid and alcohol vapor environments, Langmuir 25, (2009) 13052-13061.

[13] A.J. Barthel, S.H. Kim, Lubrication by Physisorbed Molecules in Equilibrium with Vapor at Ambient Condition-Effects of Molecular Structure and Substrate Chemistry, Langmuir 30, (2014) 6469-6478.

[14] J.X.Yu, S.H. Kim, B.J. Yu, L.M. Qian, Z.R. Zhou, Role of tribochemistry in nanowear of single-crystalline silicon, ACS Appl. Mater. Interface. 4(3), (2012) 1585-1593.

[15] X. Wang, C. Song, B. Yu, L. Chen, L. Qian, Nanowear behavior of monocrystalline silicon against SiO2 tip in water, Wear 298, (2013) 80-86.

[16] D.J. Marchand, L. Chen, Y. Meng, L. Qian, S.H. Kim, Effects of Vapor Environment and Counter-Surface Chemistry on Tribochemical Wear of Silicon Wafers, Tribol. Lett. 53, (2014) $365-372$. 
[17] L.C. Bradley, Z.R. Dilworth, A.L. Barnette, E. Hsiao, A.J. Barthel, C.G. Pantano, S.H. Kim, Hydronium Ions in Soda-lime Silicate Glass Surfaces, J. Am. Ceram. Soc. 96 (2), (2013) 458463.

[18] H. He, L. Qian, C.G. Pantano, S.H. Kim, Mechanochemial wear of soda-lime silica glass in humid envrionments, J. Am. Ceram. Soc. 97 (7), (2014) 2061-2068.

[19] N.D. Surdyka, C.G. Pantano, S.H. Kim, Environmental effects on initiation and propagation of surface defects on silicate glasses: scratch and fracture toughness study, Appl. Phys. A, 116, (2014) 519-528.

[20] D.B. Asay, S.H. Kim, Molar volume and adsorption isotherm dependence of capillary forces in nanoasperity contacts, Langmuir 23, (2007) 12174-12178.

[21] A.L. Barnette, D.B. Asay, M.J. Janik, S.H. Kim, Adsorption Isotherm and Orientation of Alcohols on Hydrophilic $\mathrm{SiO}_{2}$ under Ambient Conditions, J. Phys. Chem. C. 113, (2009) 1063210641.

[22] A. Zerr, M. Kempf, M. Schwarz, E. Kroke, M. Goken, R. Riedel, Elastic Moduli and Hardness of Cubic Silicon Nitride, J. Am. Ceram. Soc. 85 (1), (2002) 86 -90.

[23] I.L. Singer, R.N. Bolster, J. Wegand, S. Fayeulle, B.C. Stupp, Hertzian stress contribution to low friction behavior of thin MoS2 coatings, Appl. Phys. Lett. 57 (10), (1990) 995-997.

[24] M.J. Marino, E. Hsiao, Y. Chen, O.L. Eryilmaz, A. Erdemir, S.H. Kim, Understanding RunIn Behavior of Diamond-Like Carbon Friction and Preventing Diamond-Like Carbon Wear in Humid Air, Langmuir 27, (2011) 12702-12708.

[25] A.J. Barthel, M.D. Gregory, S.H. Kim, Humidity Effects on Friction and Wear Between Dissimilar Metals, Tribol. Lett. 48, (2012) 305-313.

[26] J.F. Archard, Contact and rubbing of flat surfaces, J. Appl. Phys., 24 (8), (1953) 981-988. 
[27] J. Li, C. Zhang, L. Sun, X. Lu, J. Luo, Tribochemistry and Superlubricity Induced by Hydrogen Ions, Langmuir 28, (2012) 15816-15823.

[28] T. Fischer, H. Tomizawa, Interaction of tribochemistry and microfracture in the friction and wear of silicon nitride, Wear 105, (1985) 29-45.

[29] R.C. Dante, C. Kajdas, A review and a fundamental theory of silicon nitride tribochemistry, Wear 288, (2012) 27-38.

[30] T. Fischer, W. Mullins, Chemical aspects of ceramic tribology, J. Phys. Chem. 96, (1992) $5690-5701$.

[31] C.M. Wang, X. Pan, M. Rühle, F. Riley, M. Mitomo, Silicon nitride crystal structure and observations of lattice defects, J. Mater. Sci. 31, (1996) 5281-5298.

[32] F.L. Riley, Silicon nitride and related materials, J. Am. Ceram. Soc. 83, (2000) 245-265.

[33] H. Tomizawa, T.E. Fischer, Friction and wear of silicon nitride and silicon carbide in water: hydrodynamic lubrication at low sliding speed obtained by tribochemical wear, ASLE Trans. 30, (1986) 41-46.

[34] R.S. Gates, S.M. Hsu, E.E. Klaus, Tribochemical mechanism of alumina with water, Tribo. Trans. STLE 32, (1989) 357-363.

[35] M.D. Franke, W.R. Ernst, A.S. Myerson, Kinetics of Dissolution of Alumina in Acidic Solution, AIChE Journal 33, (1987) 267-273.

[36] G. Lefèvre, M. Duc, P. Lepeut, R. Caplain, M. Fédoroff, Hydration of $\gamma$-alumina in water and its effects on surface reactivity, Langmuir 18, (2002) 7530-7537.

[37] M.G. Gee, The formation of aluminum hydroxide in the sliding wear of alumina, Wear 153, (1992) 201-227. 
[38] E. Ghali, W. Dietzel, k.U. Kainer, General and localized corrosion of magnesium alloys: a critical review, J. Mater. Eng. Perform. 13,(2004) 7-23.

[39] W.A. Lanford, P. Lamarche, T. Laursen, R. Groleau, Hydration of soda-lime glass, J. NonCryst. Solids 33,(1979) 249-266.

[40] A.P. Grosvenor, B.A. Kobe, N.S. McIntyre, Studies of the oxidation of iron by water vapour using X-ray photoelectron spectroscopy and QUASES, Surf. Sci. 572,(2004) 217-227.

[41] D. Sutton, G. Limbert, D. Stewart, R. Wood, The friction of diamond-like carbon coatings in a water environment, Friction 1, (2013) 210-221.

[42] H. Li, T. Xu, C. Wang, J. Chen, H. Zhou, H. Liu, Friction-induced physical and chemical interactions among diamond-like carbon film, steel ball and water and/or oxygen molecules, Diamond \& Related Materials 15, (2006) 1228-1234.

[43] A. Al-Azizi, O. Eryilmaz, A. Erdemir, S.H. Kim, Nano-texture for a wear-resistant and near-frictionless diamond-like carbon, Carbon 73, (2014) 403-412.

[44] M.J. Marino, E. Hsiao, L.C. Bradley, O. Eryilmaz, A. Erdemir, S.H. Kim, Is Ultra-Low Friction Needed to Prevent Wear of Diamond-Like Carbon (DLC)? An Alcohol Vapor Lubrication Study for Stainless Steel/DLC Interface, Tribol. Lett. 42, (2011) 285-291.

[45] W. Maw, F. Stevens, S. Langford, J. Dickinson, J. Single asperity tribochemical wear of silicon nitride studied by atomic force microscopy, J. Appl. Phys. 92, (2002) 5103-5109.

[46] F. Stevens, S. Langford, J. Dickinson, Tribochemical wear of sodium trisilicate glass at the nanometer size scale, J. Appl. Phys. 99, (2006) 023529.

[47] M. Ciccotti, Stress-corrosion mechanisms in silicate glasses, J. Phys. D: Appl. Phys. 42, (2009) 214006. 
[48] M. Tomozawa, Stress corrosion reaction of silica glass and water, Physics and Chemistry of Glasses-European Journal of Glass Science and Technology Part B 39, (1998) 65-69. 


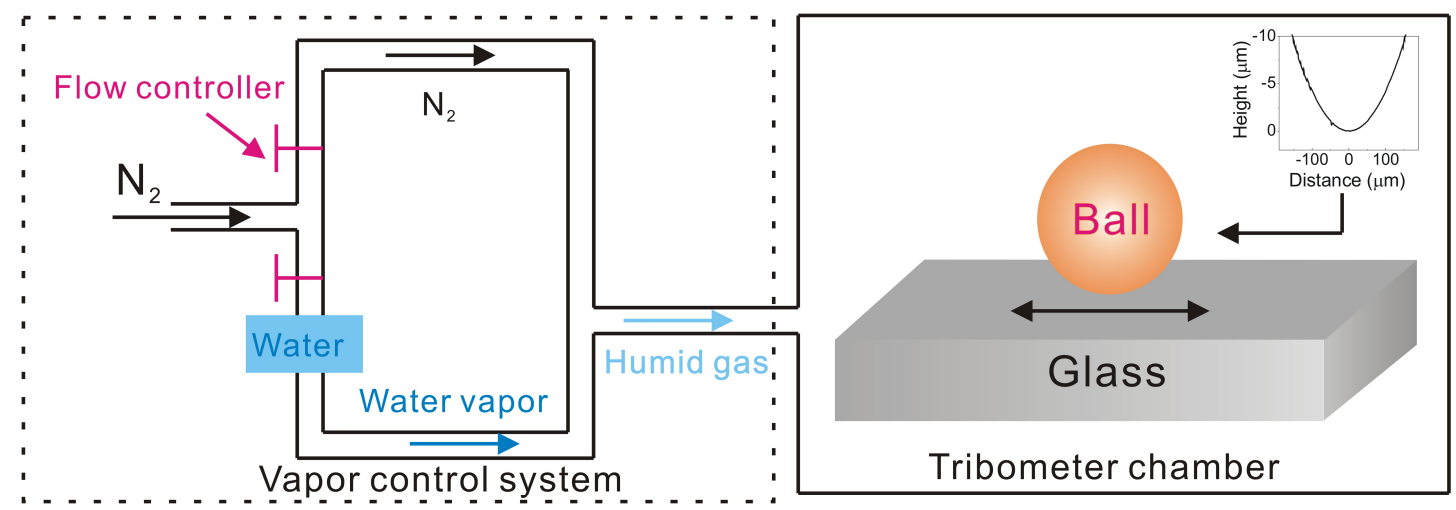

Figure 1. The schematic illustration showing the wear tests operated in a ball-on-flat tribometer with an atmosphere chamber (right part) connected to an external vapor control system (left part). The ball moves horizontally on the glass surface under a normal load of $0.2 \mathrm{~N}$. With the vapor controlling system, the relative humidity can be controlled in the range $0 \%-90 \% \mathrm{RH}$. The line profile of the pristine ball surface measured with optical profilometry is shown in the inset. 


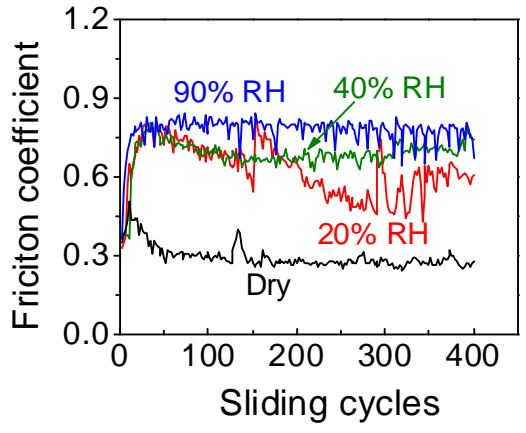

(a)

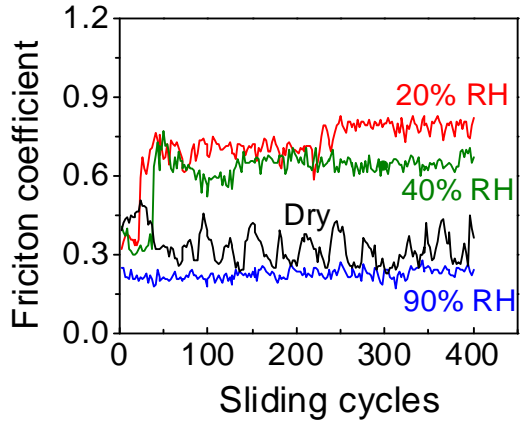

(b)

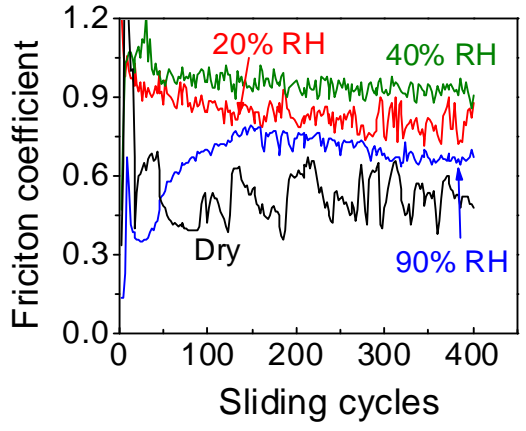

(c)

Figure 2. Friction coefficients measured when soda-lime-silica glass substrate against (a) $\mathrm{Si}_{3} \mathrm{~N}_{4}$ ball, (b) $\mathrm{Al}_{2} \mathrm{O}_{3}$ ball, and (c) stainless steel ball in various $\mathrm{RH}$ environments. 

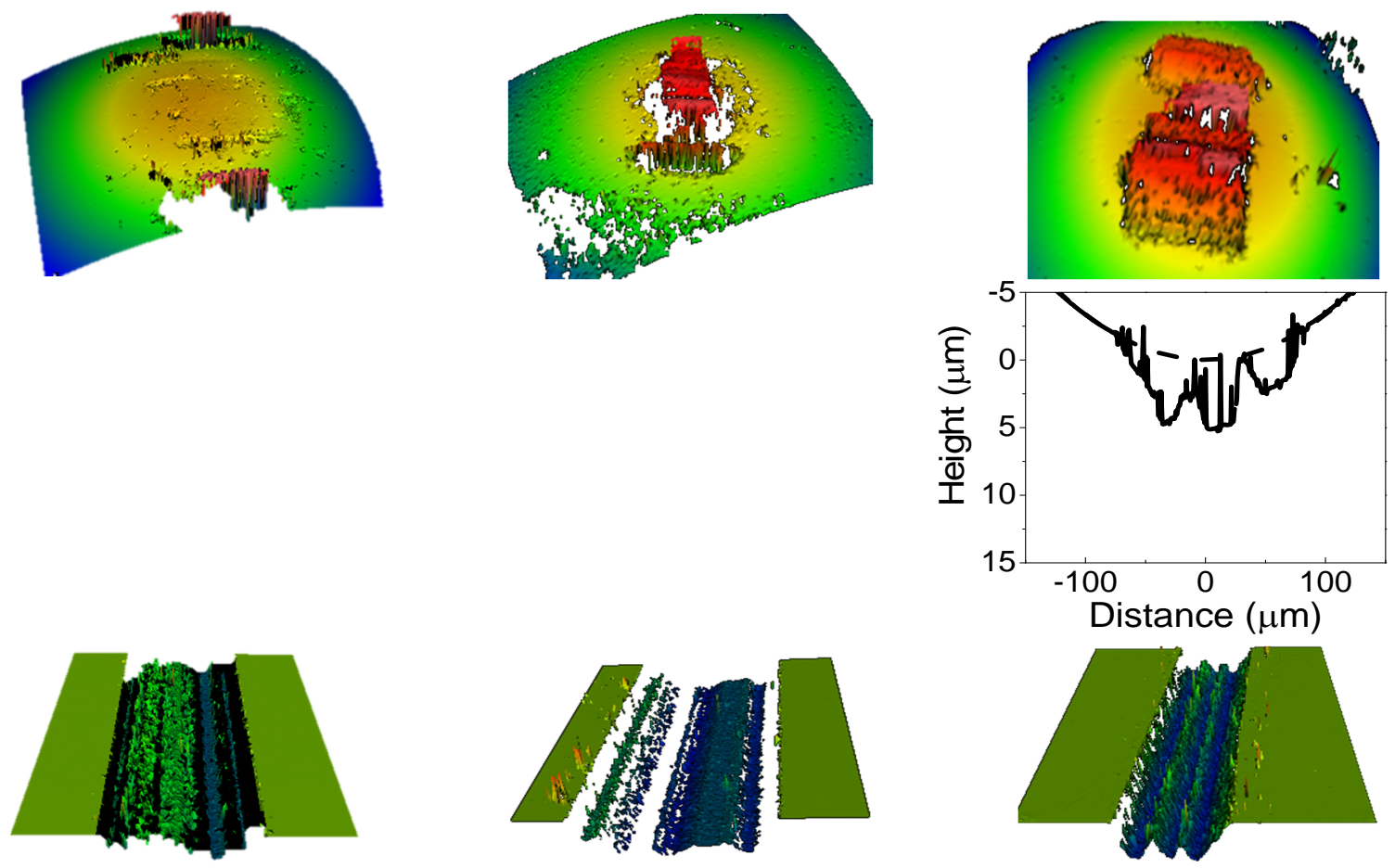

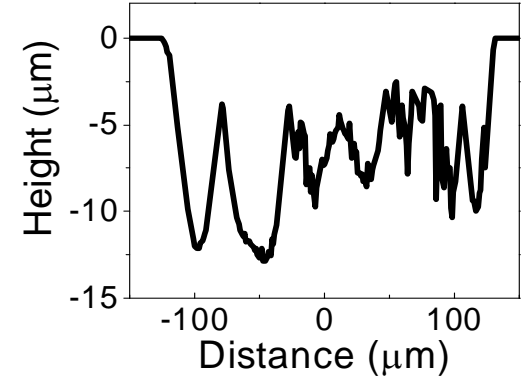

(a)

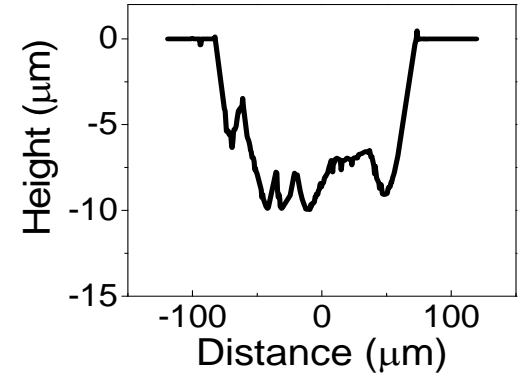

(b)

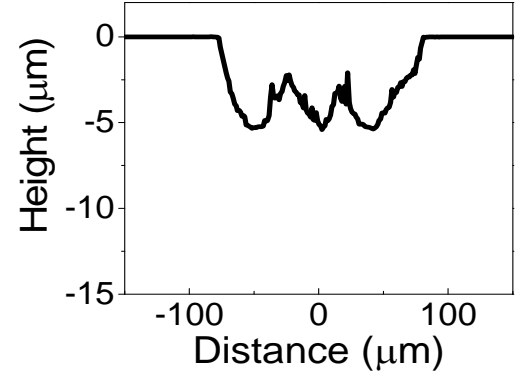

(c)

Figure 3. Line profiles of ball surfaces (upper) and soda-lime-silica glass substrates (lower) after 400 cycles of scratching at an applied load of $0.2 \mathrm{~N}$ under dry conditions. (a) $\mathrm{Si}_{3} \mathrm{~N}_{4}$ ball, (b) $\mathrm{Al}_{2} \mathrm{O}_{3}$ ball, and (c) Stainless steel ball. The line profiles of ball surfaces before and after the wear tests were combined in a single plot to show the topographic changes due to wear of the matching pair. The original ball surface is shown with dashed lines and was arbitrarily positioned at zero in the y-axis. The more negative height of flat substrate showed more wear of materials. 


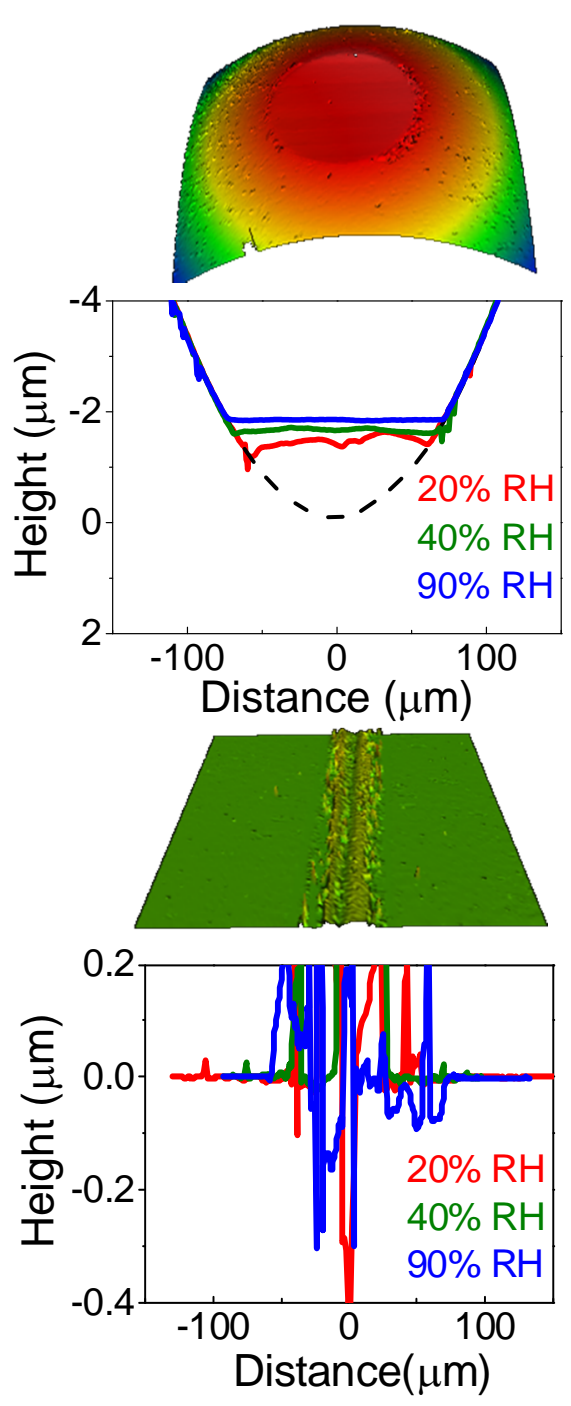

(a)
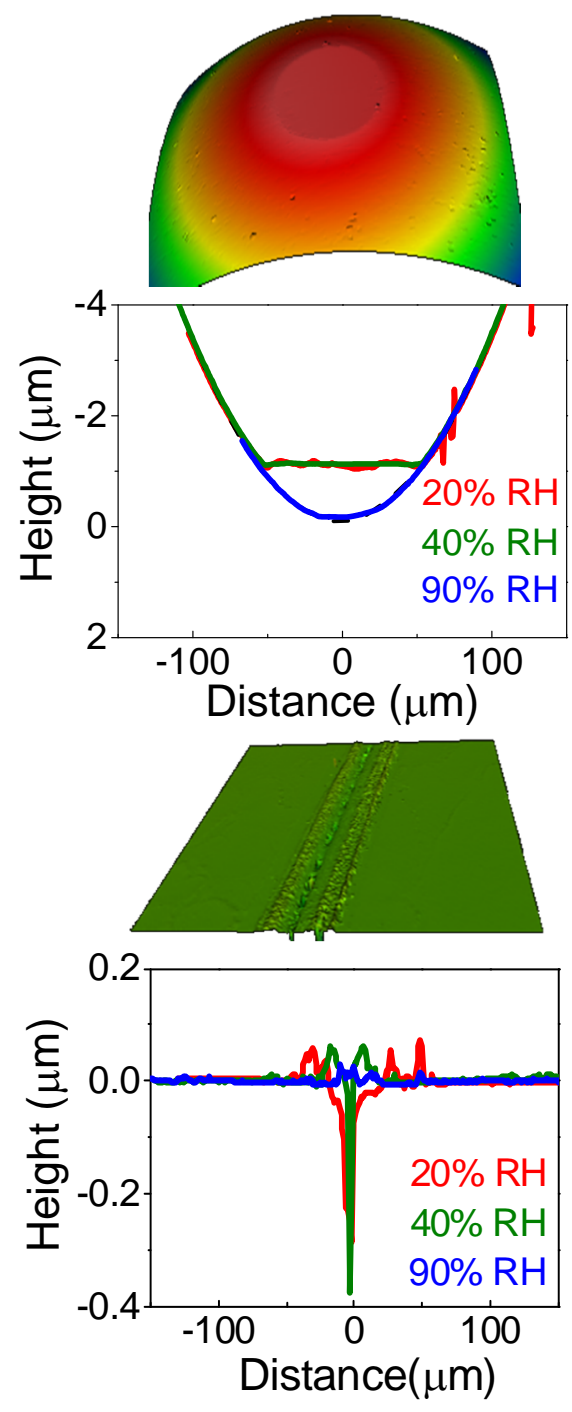

(b)

Figure 4. Characteristic optical profilometry images at $40 \% \mathrm{RH}$ and line profiles of various balls surface (upper) and soda-lime-silica glass substrates (lower) after 400 cycles of scratching at an applied load of $0.2 \mathrm{~N}$ under various humidity conditions. (a) $\mathrm{Si}_{3} \mathrm{~N}_{4}$ ball. (b) $\mathrm{Al}_{2} \mathrm{O}_{3}$ ball. 


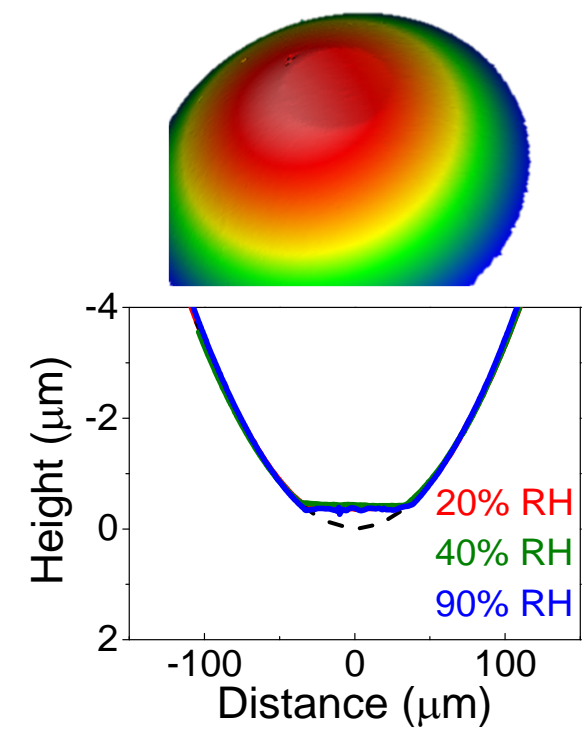

(a)

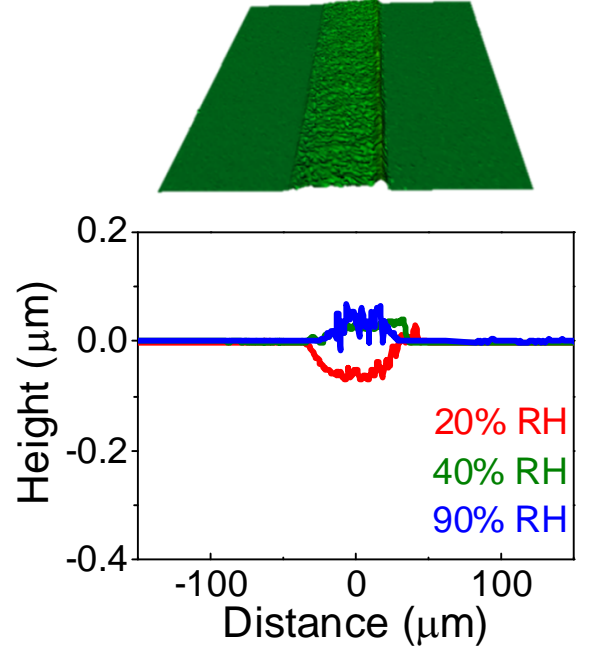

(b)

Figure 5. Characteristic optical profilometry images at 40\% RH (upper) and line profiles of stainless steel ball surface and soda-lime-silica glass substrates (lower) after 400 cycles of scratching at an applied load of $0.2 \mathrm{~N}$ under various humidity conditions. (a) Steel ball. (b) Soda-lime glass. 

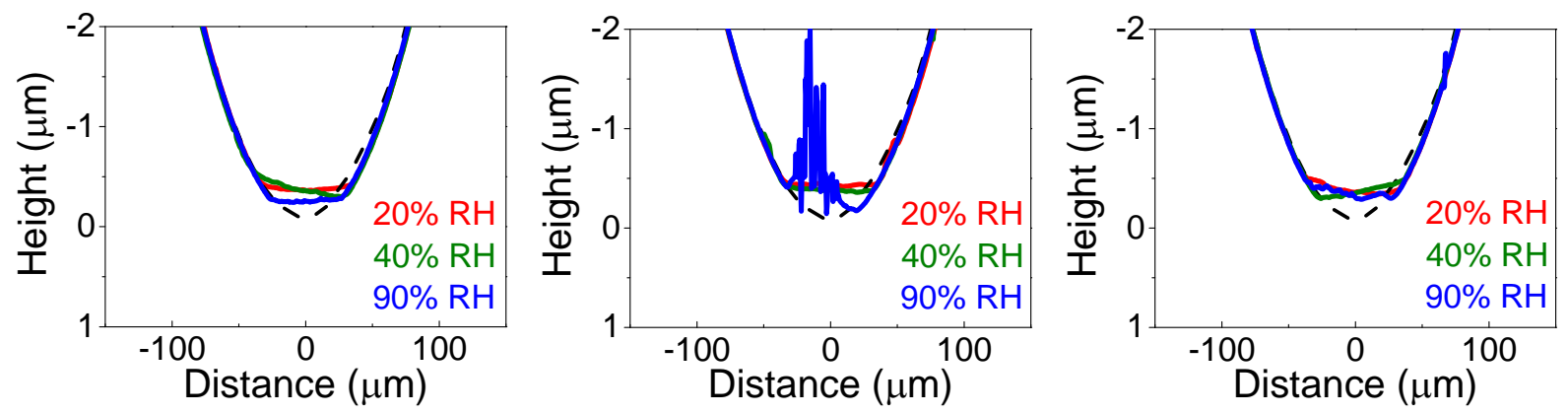

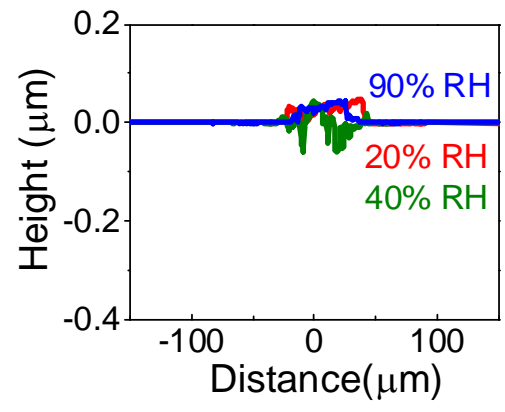

(a)

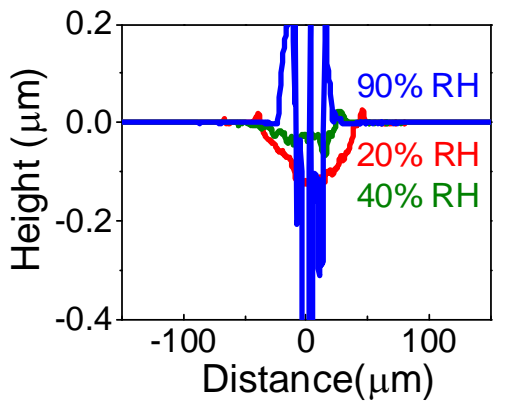

(b)

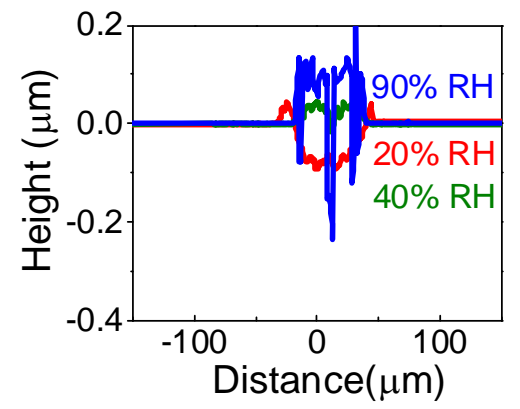

(c)

Figure 6. Line profiles of stainless steel balls surface (upper) against various glass substrates (lower) after 400 cycles of scratching at an applied load of $0.2 \mathrm{~N}$ under various humidity conditions. (a) Borosilicate glass. (b) Sodium aluminosilicate glass. (c) Potassium aluminosilicate glass. 